\title{
HUBUNGAN ANTARA PENGETAHUAN DENGAN SIKAP REMAJA DALAM MENGHADAPI MENARCHE DI DESA RAGAWACANA KECAMATAN KRAMATMULYA KABUPATEN KUNINGAN
}

\author{
${ }^{1}$ Yona Septina, ${ }^{2}$ Anisa Nurohmah, ${ }^{3}$ Siti Nunung Nurjannah, ${ }^{4}$ Anggit Kartikasari \\ Sekolah Tinggi Ilmu Kesehatan Kuningan Garawangi \\ yonaseptina@stikku.ac.id
}

\begin{abstract}
Abstrak
Rata-rata usia menarche di Indonesia adalah 13 tahun (20,0\%) dengan kejadian lebih awal pada usia kurang dari 9 tahun dan ada yang lebih lambat sampai 20 tahun serta terdapat 7,8\% yang melaporkan belum haid. Secara nasional rata-rata usia menarche 13-14 tahun terjadi pada $37,5 \%$ anak Indonesia. Tujuan dari penelitian ini adalah untuk mengetahui faktor penyebab mengapa remaja di Desa Ragawacana belum mengetahui tentang menarche dan apabila sudah diketahui hasilnya maka dapat dilakukan upaya agar remaja dapat memperoleh pengetahuan lebih tentang menarche dan dapat menyikapinya dengan baik. Jenis penelitian yang digunakan adalah korelasional. Metode yang digunakan cross sectional. Teknik pengambilan sampel yaitu menggunakan Random Sampling dengan Populasi sebanyak 123 orang dan jumlah yang dijadikan sampel sebanyak 94 responden. Hasil analisis univariat, persentase tingkat pengetahuan tertinggi dengan kategori baik sebanyak 59 responden $(62,8 \%)$, sedangkan persentasi sikap tertinggi dengan kategori tidak baik sebanyak 49 responden $(52,1 \%)$. Hasil analisis bivariat, didapatkan bahwa nilai $\rho$ value $<0,05$ yang artinya terdapat hubungan antara pengetahuan dengan sikap remaja dalam menghadapi menarche. Simpulan dari penelitian ini adalah terdapat hubungan antara pengetahuan dengan sikap remaja dalam menghadapi menarche. Saran bagi remaja putri diharapkan mampu meningkatkan pengetahuan mengenai menarche dan juga dapat menerima serta mampu menyikapi perubahan fisiologis maupun psikologis serta emosional yang terjadi pada masa menarche.
\end{abstract}

Kata Kunci : Pengetahuan, Sikap, Menarche

Pendahuluan

Kematangan mental, emosional, social, dan fisik merupakan rangkaian proses peralihan dari masa pubertas ke dewasa, dan merupakan proses masa remaja. Perkembangan yang ditandai dengan 
JOURNAL OF MIDWIFERY CARE :

VOL. 01 No. 02, JUNI 2021

DOI: $10.34305 / j m c . v 1 i 02.262$
Ciptaan disebarluaskan di bawah

Lisensi Creative Commons

Atribusi-NonKomersial-

BerbagiSerupa 4.0 Internasional kematangan organ seksual dan tercapainya kemampuan untuk bereproduksi adalah masa pubertas, dimana salah satu ciri dari tanda pubertas seorang perempuan yaitu dengan terjadinya menstruasi pertama (menarche) (Abdullah, 2009). Menstruasi atau haid didefinisikan perdarahan vagina secara berkala akibat terlepasnya lapisan endometrium uterus. (Janiwarty \& Pieter, 2013) Proses biologis yang terkait dengan pencapaian kematangan seks, kesuburan, ketidak hamilan, normalitas, kesehatan tubuh, dan bahkan pembaharuan tubuh itu sendiri adalah menarch (Abdullah, 2009).

Menurut (Kusmiran, 2012) sekitar 1 milyar manusia atau setiap 1 di antara 6 penduduk dunia adalah remaja. Sebanyak $85 \%$ diantaranya hidup di Negara berkembang. Berdasarkan kriteria WHO umur remaja berkisar antara 10-19 tahun. Angka kejadian menarche di dunia cukup besar, rata-rata lebih dari 50\%. Berdasarkan data Badan Koordinasi Keluarga Berencana Nasional, pada tahun 2014 jumlah remaja usia 15-24 tahun yang mengalami menarche sebanyak 40,75 juta, sementara jumlah remaja usia 1014 tahun yang mengalami menarche sebanyak 22,7 juta.

Berdasarkan laporan responden yang sudah mengalami haid berusia lebih awal pada usia kurang dari 9 tahun dan ada yang lebih lambat sampai 20 tahun serta 7,9\% tidak menjawab/lupa. Terdapat 7,8\%, sedangkan rata-rata adalah 13 tahun yaitu sebanyak (20,0\%) dengan. Secara nasional rata-rata usia menarche 13-14 tahun terjadi pada 37,5\% anak Indonesia (Badan Penelitian dan Pengembangan Kesehatan Kementerian Kesehatan RI, 2016)

Hasil Survei Penduduk Antar Sensus 2015, menunjukkan bahwa penduduk usia 15-24 tahun mencapai 42.061,2 juta atau sebesar 16,5 persen dari total penduduk Indonesia. Jumlah penduduk usia remaja ini akan mengalami peningkatan hingga tahun 2030 dan kemudian menurun sesudahnya berdasarkan hasil Proyeksi penduduk (Statistik, 2016).

Hasil cakupan deteksi tumbuh kembang dan pelayanan kesehatan remaja, diketahui jumlah remaja sebanyak 15.227 jiwa, yang berkonsultasi dengan tenaga kesehatan sebanyak 7.244 jiwa, persentase remaja yang berkonsultasi dengan tenaga kesehatan sebesar 47,57\%. Dari 47,57\% remaja yang berkonsultasi tersebut diantaranya adalah remaja puteri yang berkonsultasi tentang menstruasi dan gangguan menstruasi, sedangkan beberapa diantaranya mendapatkan pelayanan kesehatan akibat gangguan menstruasi. 
JOURNAL OF MIDWIFERY CARE :

VOL. 01 No. 02, JUNI 2021

DOI: $10.34305 / j m c . v 1 i 02.262$
Ciptaan disebarluaskan di bawah

Lisensi Creative Commons

Atribusi-NonKomersial-

BerbagiSerupa 4.0 Internasional
Dinas Kesehatan Kabupaten Kuningan pada tahun 2017.

Berdasarkan hasil studi pendahuluan yang dilakukan di Desa Ragawacana Kecamatan Kramatmulya Kabupaten Kuningan pada bulan Agustus didapatkan hasil bahwa jumlah remaja di Desa Ragawacana sebanyak 202 orang, dari 152 orang diantaranya berusia 11-14 tahun dan 123 orang yang sudah mengalami menarche, sedangkan 29 diantaranya belum mengalami menarche (Kesehatan, 2014). Hasil dari jumlah 123 orang remaja yang sudah mengalami menarche, didapatkan persentase sebanyak $90 \%$ remaja yang belum mengetahui tentang cara menghadapi menarche. Tujuan dari penelitian ini adalah untuk mengetahui Hubungan Antara Pengetahuan Dengan Sikap Remaja Dalam Menghadapi Menarche Di Desa Ragawacana Kecamatan Kramatmulya Kabupaten Kuningan.

\section{Metode}

Jenis penelitian ini adalah penelitian analitik, penelitian analitik adalah penelitian yang menekankan adanya hubungan antara satu variabel dengan variabel lainnya (Dewi Laelatul Badriah, 2009). Rancangan penelitian pada penelitian ini adalah cases control (Arikunto, 2006), sampel dalam penelitian ini yaitu remaja sebagai responden yang ada di Desa Ragawacana Kecamatan Kramatmulya Kabupaten Kuningan, berjumlah 94 orang. Pengambilan sampel dalam penelitian ini menggunakan teknik rumus slovin, variabel bebas dalam penelitian ini adalah pengetahuan, sedangkan variabel terikat dalam penelitian ini adalah sikap remaja puteri dalam menghadapi menarche. Instrumen pada penelitian ini yaitu kuesioner, formulir observasi, formulirformulir lain yang berkaitan dengan pencatatan data dan sebagainya.

\section{Hasil}

Analisis Univariat

Distribusi frekuensi tingkat pengetahuan remaja tentang menarche di Desa Ragawacana Kecamatan Kramatmulya Kabupaten Kuningan.

Tabel 1. Pengetahuan dan Sikap Remaja Dalam Menghadapi Menarche di Desa Ragawacana Kecamatan Kramatmulya Kabupaten Kuningan

\begin{tabular}{ccc}
\hline Variabel & Frekuensi $(\boldsymbol{f})$ & Persentase (\%) \\
\hline Pengetahuan & & 62,7 \\
Baik & 59 & 37,2 \\
Kurang & 35 & 100 \\
Total & 94 & \\
\hline
\end{tabular}




\begin{tabular}{ccc}
\hline Variabel & Frekuensi $(\boldsymbol{f})$ & Persentase (\%) \\
\hline Sikap & & \\
Baik & 44 & 46,8 \\
Tidak Baik & 50 & 53,1 \\
Total & 94 & 100 \\
\hline Sumber: Hasil Penelitian & &
\end{tabular}

Sumber: Hasil Penelitian

Berdasarkan tabel diatas dapat Berdasarkan tabel diatas dapat diketahui diketahui bahwa dari 94 responden, bahwa dari 94 responden persentase persentase tertinggi ada pada kriteria baik yaitu sebanyak 59 responden atau sekitar $(62,8 \%)$, sedangkan persentase terendah ada pada kriteria kurang sebanyak 35 responden atau sekitar $(37,2 \%)$.

Distribusi Frekuensi Sikap Remaja Dalam Menghadapi Menarche di Desa Ragawacana Kecamatan Kramatmulya Kabupaten Kuningan. terbanyak ada pada kriteria tidak baik yaitu sebanyak 49 responden atau sekitar $(52,1 \%)$, sedangkan persentase terendah ada pada kriteria baik yaitu sebanyak 45 responden atau sekitar (47,9\%).

Analisis Bivariat

Hubungan Antara Pengetahuan Dengan Sikap Remaja Dalam Menghadapi Menarche di Desa Ragawacana Kecamatan Kramatmulya Kabupaten Kuningan.

Tabel 2 Hubungan Pengetahuan Dengan Sikap Remaja Dalam Menghadapi Menarche di Desa Ragawacana Kecamatan Kramatmulya Kabupaten Kuningan.

\begin{tabular}{|c|c|c|c|c|c|c|c|}
\hline \multirow{3}{*}{$\begin{array}{c}\text { Tingkat } \\
\text { Pengetahuan }\end{array}$} & \multicolumn{4}{|c|}{ Sikap } & \multirow{2}{*}{\multicolumn{2}{|c|}{ Total }} & \multirow{3}{*}{ p-Value } \\
\hline & \multicolumn{2}{|c|}{ Tidak Baik } & \multicolumn{2}{|c|}{ Baik } & & & \\
\hline & $\mathbf{N}$ & $\%$ & $\mathbf{N}$ & $\%$ & $\mathbf{N}$ & $\%$ & \\
\hline Kurang & 35 & 37,2 & 0 & 0 & 35 & 37,2 & \multirow{3}{*}{0,001} \\
\hline Baik & 15 & 14,9 & 44 & 47,9 & 59 & 62,8 & \\
\hline \multicolumn{5}{|c|}{ Jumlah } & 94 & 100 & \\
\hline
\end{tabular}

Sumber : Hasil Penelitian

Dari tabel 2 diatas dapat diketahui bahwa sebagian besar responden berada pada kategori baik yaitu sebanyak 45 responden. Jumlah terbanyak yaitu responden berada pada kategori tingkat pengetahuan baik dan sikap baik sebanyak 45 responden $(47,9 \%)$, sedangkan jumlah terendah berada pada kategori tingkat pengetahuan kurang dan sikap baik yaitu sebanyak 0 responden $(0 \%)$.

Berdasarkan hasil uji Chi-square yang dilakukan pada responden mengenai hubungan antara pengetahuan dengan sikap remaja dalam menghadapi menarche, di 
JOURNAL OF MIDWIFERY CARE :

VOL. 01 No. 02, JUNI 2021

DOI: $10.34305 / j m c . v 1 i 02.262$ dapatkan $\rho$ value sebesar 0,001 lebih kecil dari $0,05(0,001<0,05)$, sehingga $\mathrm{Ha}$ diterima yang menyatakan bahwa adanya hubungan antara pengetahuan dengan sikap remaja dalam menghadapi menarche di Desa Ragawacana Kecamatan Kramatmulya Kabupaten Kuningan.

\section{Pembahasan}

Analisis Univariat

Pengetahuan Remaja Tentang Menarche Di Desa Ragawacana Kecamatan Kramatmulya Kabupaten Kuningan.

Pengetahuan adalah hasil "tahu" ketika seseorang melakukan pengamatan terhadap suatu objek tertentu. Pengetahuan diperoleh manusia melalui penglihatan dan pendengaran (Notoatmojo, 2010). Berdasarkan penelitian yang dilakukan penulis di Desa Ragawacana Kecamatan Kramatmulya Kabupaten Kuningan didapatkan hasil bahwa frekuensi responden yang berpengetahuan baik lebih banyak di antara responden yang berpengetahuan kurang, tetapi lebih banyak responden yang berpengetahuan baik hanya berasal dari usia 13-14 tahun saja jika dibanding dengan responden yang berusia 11-12 tahun ratarata berpengetahuan kurang, hal ini tentu menjadi masalah karena itu artinya remaja usia 11-12 tahun belum mendapatkan pengetahuan yang cukup mengenai menstruasi atau menarche, bahkan beberapa orang diantaranya belum mengetahui secara jelas apa sebenarnya yang dimaksud dengan menarche (menstruasi pertama) itu sendiri, sedangkan pada remaja usia 13-14 tahun yang rata-rata berpengetahuan baik pun tidak semuanya tahu ataupun mengerti tentang menarche, bahkan ada beberapa orang diantara mereka yang asal menjawab ataupun mencontek dari jawaban temannya. Pengetahuan sangat diperlukan sebagai dorongan psikis dalam menumbuhkan diri maupun dorongan sikap dan perilaku setiap hari, sehingga dapat dikatakan bahwa pengetahuan merupakan stimulus terhadap tindakan seseorang (Notoatmojo, 2010).

Maka dari itu penulis tertarik untuk melakukan penelitian tentang menarche agar dapat diketahui secara pasti apa penyebab dari ketidaktahuan remaja, sehingga dengan melakukan penelitian ini diharapkan orang tua remaja dapat memberikan informasi dan pengetahuan tentang menstruasi kepada remaja.

Sikap Remaja Dalam Menghadapi Menarche di Desa Ragawacana Kecamatan Kramatmulya Kabupaten Kuningan.

Sikap dapat diartikan sebagai salah satu pencetus teori pengukuran modern yaitu sebagai afeksi atau perasaan terhadap sebuah rangsangan (Azwar, 2005). Arti lain dari 
JOURNAL OF MIDWIFERY CARE :

VOL. 01 No. 02, JUNI 2021

DOI: 10.34305/jmc.v1i02.262
Ciptaan disebarluaskan di bawah

Lisensi Creative Commons

Atribusi-NonKomersial-

BerbagiSerupa 4.0 Internasional

Menurut asumsi peneliti yang didasarkan pada hasil penelitian yang dilakukan bahwa sikap terhadap menarche itu dipengaruhi oleh beberapa faktor, salah satu faktor yang mempengaruhinya adalah kurangnya pemahaman yang ditanamkan orang tua kepada anaknya, karena seringkali orang tua merasa bahwa menarche atau menstruasi pertama itu merupakan hal yang tabu untuk dibicarakan sehingga anak juga akan menganggap menarche sebagai hal yang tabu, dan akhirnya anak tersebut tidak ada keinginan untuk mencari tahu lebih dalam tentang menarche karena dianggap tabu, padahal peran orang tua dalam pemahaman tentang menarche sangatlah penting bagi anak, hal tersebut juga dikemukakan pada sebuah teori.

Remaja dalam mempersiapkan Setiap manusia memiliki sikap yang berbeda-beda terhadap sesuatu objek tertentu. Ini disebabkan oleh berbagai faktor yang ada pada individu masing-masing seperti adanya perbedaan dalam bakat, minat, pengalaman, pengetahuan, intensitas perasaan dan juga situasi lingkungan, begitu juga dengan sikap manusia kepada sesuatu yang sama mungkin saja tidak sama, sikap juga merupakan sebuah perilaku yang dinamis, bisa berubah, dibentuk atau dipengaruhi. datangnya menarche sangat memerlukan dukungan, dukungan itu juga dapat diperoleh dari lingkungan keluarga (orang tua), lingkungan sekolah (guru), lingkungan teman sebaya, dan lingkungan masyarakat (sosial budaya dan media massa), lingkungan dalam keluarga merupakan lingkungan pertama dan utama bagi perkembangan anak dan dukungan itu baik berupa dukungan secara emosional, informasi, penghargaan dan instrumental (Anurogo, 2009). 
JOURNAL OF MIDWIFERY CARE :

VOL. 01 No. 02, JUNI 2021

DOI: $10.34305 / j m c . v 1 i 02.262$
Ciptaan disebarluaskan di bawah

Lisensi Creative Commons Atribusi-NonKomersial-

BerbagiSerupa 4.0 Internasional
Analisis Bivariat

Berdasarkan hasil penelitian yang dilakukan didapatkan hasil bahwa jumlah persentasi tertinggi berada pada kategori pengetahuan baik dan sikap baik yaitu sebanyak 45 responden $(47,9 \%)$, hal ini berarti remaja yang memiliki tingkat pengetahuan baik, sikapnya juga baik. Hal ini sesuai dengan salah satu teori.

Menurut (Notoatmojo, 2010) menyatakan bahwa pengetahuan, sikap, kepercayaan, tradisi dari orang yang bersangkutan, dapat dipengaruhi oleh perilaku atau sikap seseorang atau masyarakat tentang kesehatan, juga ditentukan oleh ketersediaan fasilitas, sikap dan perilaku para petugas kesehatan terhadap kesehatan.

Berdasarkan penelitian yang dilakukan oleh penulis bahwa remaja yang memiliki pengetahuan baik sikapnya juga baik, sedangkan remaja yang memiliki pengetahuan kurang sikapnya tidak baik , pernyataan tersebut dilihat dari banyaknya persentase dari masing-masing kategori yang ada, sehingga penulis menyimpulkan bahwa pengetahuan dapat mempengaruhi sikap seseorang, karena pengetahuan dengan sikap saling berhubungan pernyataan ini dibuktikan dengan hasil uji Chi Square yang dilakukan kepada responden dan didapatkan hasil $\rho$ value 0,001 yang berarti nilai $\rho$ value $<0,05$ maka berarti terdapat hubungan yang signifikan antara pengetahuan dengan sikap remaja dalam menghadapi menarche.

Hal ini juga dikemukakan oleh (Azwar, 2005) bahwa sikap manusia terbentuk melalui proses di dalam lingkungan keluarga, sekolah maupun masyarakat. Saat terjadi proses sosial terjadi hubungan timbal balik antara individu dan sekitarnya, melalui proses sosial yang terjadi selama hidupnya, dimana individu mendapatkan informasi dan pengalaman dan sikap manusia tidak terbentuk sejak manusia dilahirkan sikap pada setiap individu dapat berbeda, jika suka atau setuju terhadap suatu objek maka akan mendekat, mencari tahu, dan bergabung, sebaliknya jika tidak suka atau tidak setuju maka akan menghindar atau menjauhi. Interaksi dan hubungan tersebut kemudian membentuk pola sikap individu dengan sekitarnya (Hurlock, 2006).

\section{Kesimpulan}

Gambaran pengetahuan remaja dalam menghadapi menarche sebagian besar baik yaitu sebanyak 59 responden (62,8\%). Gambaran sikap remaja dalam menghadapi menarche sebagian besar tidak baik yaitu sebanyak 49 responden (52,1\%). Berdasarkan hasil uji Chi Square didapat bahwa nilai $\rho$ value yaitu $0,001<0,05$ maka 
JOURNAL OF MIDWIFERY CARE :

VOL. 01 No. 02, JUNI 2021

DOI: $10.34305 / j m c . v 1 i 02.262$
Ciptaan disebarluaskan di bawah

Lisensi Creative Commons

Atribusi-NonKomersial-

BerbagiSerupa 4.0 Internasional
Ha diterima yang berarti terdapat hubungan antara pengetahuan dengan sikap remaja dalam menghadapi menarche di Desa Ragawacana Kecamatan Kramatmulya Kabupaten Kuningan.

\section{Saran}

Penelitian ini diharapkan mampu dijadikan pelajaran bagi orang tua remaja agar dapat lebih bisa membimbing dan memberikan pemahaman kepada remaja mengenai menarche.

\section{Daftar Pustaka}

Abdullah. (2009). Mitos Menstruasi: Konstruksi Budaya atas Realitas Gender. Available Online: Www. Google.Co.Id. 25 Maret 2009.

Anurogo, D. (2009). Psikologi Permasalahan pada Remaja.

Arikunto, S. (2006). Metode Penelitian Kualitatif. Bumi Aksara.

Azwar, S. (2005). Sikap Manusia Teori dan Pengukurannya. Pustaka Pelajar.

Badan Penelitian dan Pengembangan Kesehatan Kementerian Kesehatan RI. (2016). Riset Kesehatan Dasar.

Dewi Laelatul Badriah. (2009). Metodologi Penelitian Ilmu-Ilmu Kesehatan. Multazam.

Gerungan, W. A. (2004). Psikologi Sosial. PT Refika Aditama.
Hurlock, E. B. (2006). Psikologi Perkembangan Suatu Pendekatan Sepanjang Rentang Kehidupan. Erlangga.

Janiwarty, B., \& Pieter, H. Z. (2013). Pendidikan Psikologi untuk Bidan Suatu Teori dan Terapannya. Rapha Publishing.

Kesehatan, D. (2014). Profil Kesehatan Jawa Barat Tahun 2014. 2016-01-25. https://drive.google.com/file/d/0ByBl q3oFysQ7N11OaGdST3FFdmM/view

Kusmiran, E. (2012). Kesehatan Reproduksi Remaja dan Wanita. Salemba Medika.

Notoatmojo. (2010). Ilmu Kesehatan Masyarakat Prinsip-Prinsip Dasar. Rineka Cipta.

Soetjiningsih. (2004). Tumbuh Kembang Remaja dan Permasalahanya. PT. Rhineka Cipta.

Statistik, B. P. (2016). Data Statistik I ndonesia. Jumlah Penduduk menurut Kelompok Umur, Jenis Kelamin, Provinsi, dan Kabupaten/Kota, 2005. 